\title{
EXTRATOS VEGETAIS E ÓLEOS ESSENCIAIS NA MICROPROPAGAÇÃO DE VIDEIRA CV. BORDÔ
}

\section{EXTRACTS AND ESSENTIAL OILS IN MICROPROPAGATION OF GRAPEVINE CV. BORDÔ}

\author{
Bruna SPINARDI ${ }^{1}$ \\ Aline Machado RODRIGUES ${ }^{2}$ \\ Ricardo Antonio $\mathrm{AYUB}^{3}$ \\ Carolina Weighert GALVÃO ${ }^{3}$ \\ Domingos Sávio NUNES ${ }^{4}$
}

\begin{abstract}
RESUMO
A micropropagação da videira é utilizada com diversos objetivos, entre eles a multiplicação rápida de plantas, propagação de novos híbridos e obtenção de matrizes livres de patógenos. A utilização de extratos vegetais com ação antiviral na micropropagação mostra-se como uma forma alternativa e mais econômica na obtenção de matrizes livres de vírus. Este trabalho teve como objetivo testar os extratos aquosos de Dalbergia monetaria (spray-dryer e liofilizada) e os óleos essenciais de Melaleuca alternifolia e Calendula officinalis em diferentes concentrações na micropropagação de videira cv. Bordô. Os parâmetros avaliados foram: número de estacas, comprimento médio dos brotos, número de folhas, número de raízes por micro-estaca e comprimento da raiz principal. O extrato de $D$. monetaria spray-dry, reduziu o número de estacas e folhas, porém, foi efetivo no aumento do comprimento médio dos brotos e da raiz principal. $D$. monetaria liofilizado aumentou o número de raízes. Para calêndula não houve efeito, porém para Melaleuca alternifólia houve uma redução no número de estacas de modo linear com o aumento da concentração. Embora não se tenha benefícios diretos na micropropagação, este estudo serve de base na busca por substâncias antivirais, pois os mesmos não foram fitotóxicos.
\end{abstract}

Palavras chave: Calendula officinalis, Melaleuca alternifolia; Dalbergia monetaria; cultura de tecidos

\section{ABSTRACT}

Micropropagation of the grapevine is used with several objectives, including the rapid multiplication of plants, propagation of new hybrids and to obtain specific pathogen-free arrays. The use of plant extracts with antiviral action in micropropagation shows up as an alternative and more economical to obtain virus-free arrays. This study aimed to test the aqueous extract of Dalbergia monetaria (spray-dry and freeze-dried) and essential oils of Melaleuca and Calendula officinalis at different concentrations in the micropropagation of grapevine cv. Bordeaux. The parameters evaluated were: number of cuttings, the average length of shoots, number of leaves, number of roots and micro-cutting and the main root. The extract of $D$. monetary spray-dryer, reduced the number of cuttings and leaves, however, was effective in increasing the average length of shoots and root. $D$. monetary freeze increased the number of roots. To marigold no effect, but to Melaleuca alternifolia was a reduction in the number of poles in a linear fashion with increasing concentration. Although no direct benefits in micropropagation, this study is based on the search for antiviral substances, because they were not phytotoxic.

Key-words: Calendula officinalis; Melaleuca alternifolia; Dalbergia monetaria; tissue culture

\footnotetext{
${ }^{1}$ Graduanda em Ciências Biológicas pela Universidade Estadual de Ponta Grossa - UEPG, Departamento de Fitotecnia e Fitossanidade, Av. Carlos Cavalcante, 4748, 84030-900 - Ponta Grossa, PR, Brasil, email: bruspin@hotmail.com

${ }^{2}$ Graduanda em Técnico em Agroindústria pela Universidade Tecnológica Federal do Paraná - UTFPR, email: alineamr@hotmail.com

${ }^{3}$ Prof. Dr., Bolsista Produtividade da Fundação Araucaria, Universidade Estadual de Ponta Grossa - UEPG, Departamento de Fitotecnia e Fitossanidade, Av. Carlos Cavalcante, 4748, 84030-900 - Ponta Grossa, PR, Brasil. * Autor para contato: rayub@uepg.br

${ }^{4}$ Prof. Dr. Universidade Estadual de Ponta Grossa,Departamento de Biologia, Av. Carlos Cavalcante, 4748, 84030-900 - Ponta Grossa, PR, Brasil.

${ }^{5}$ Prof. Dr. Universidade Estadual de Ponta Grossa - UEPG, Departamento de Química.
} 
SPINARDI, B. et al. Extratos vegetais...

\section{INTRODUÇÃO}

Uma das atividades de distinta importância econômica no Brasil é o cultivo da videira. Hoje, o Estado do Paraná é o terceiro maior produtor de uvas do Brasil, destacando-se a produção de uvas finas para mesa, ficando atrás apenas do Rio Grande do Sul e de São Paulo (Botelho \& Pires, 2009).

A videira cv. Bordô, na década de 1850 despertou interesse dos viticultores europeus devido à resistência ao oídio (Uncinula necator), moléstia que naquela época causava enorme prejuízo à viticultura mundial (Grigoletti \& Sonego, 1993). Sua expansão deu-se devido à fácil adaptação à variabilidade de condições edafoclimáticas, boa produtividade, longevidade e relativa rusticidade (Zanuz, 1991; Camargo, 1994), sendo bastante utilizado para elaboração de vinho tinto, suco, vinagre, geléias e, por sua precocidade, também consumida in natura (Rizzon et al., 2000).

A propagação in vitro da videira é utilizada com diversos objetivos, entre eles a multiplicação rápida de plantas, propagação de novos híbridos e obtenção de matrizes livres de patógenos, tornando -se uma alternativa viável para a multiplicação de videiras (Dzazio et al., 2002; Coletto et al., 2008). A utilização de extratos vegetais com ação antiviral na micropropagação mostra-se como uma forma alternativa e mais econômica na obtenção de matrizes livres de vírus.

O óleo essencial de Melaleuca alternifolia (MA) apresenta atividade antiviral, demonstrada pela primeira vez ao se pulverizar plantas de Nicotiniana glutinosa infectadas como vírus do mosaico do tabaco (Bishop, 1995). O extrato de flores de Calendula officinalis (calêndula) (CO) inibiu a replicação do vírus da imunodeficiência humana (HIV-1) (Kalvatchev, 1997) porém ainda não há relatos de testes deste composto em vegetais. Já o extrato aquoso de Dalbergia monetaria L. (DM) contém proantocianidinas (Nunes et al., 1989), substâncias que podem apresentar importante atividade antiviral (Shahat et al., 2002). Sendo assim, acredita-se que estes compostos possam apresentar atividade antiviral em vegetais, solucionando o problema da propagação de vírus em diversas espécies. Contudo, é necessário avaliar a fitoxicidade destas substâncias, neste caso a videira cv. Bordô, para posteriormente realizar as análises moleculares pertinentes, para verificação do poder antiviral.

Diante do exposto, este trabalho teve como objetivo testar o efeito de diferentes extratos vegetais e óleos essenciais na micropropagação da videira cv. Bordô, bem como a viabilidade do uso deste compostos em meio de cultura sem que o crescimento e o desenvolvimento das plântulas seja prejudicado.

\section{MATERIAL E MÉTODOS}

O experimento foi conduzido no Laboratório de Biotecnologia aplicada á Fruticultura da Universidade Estadual de Ponta Grossa-PR, no período de Março de 2009 a Fevereiro de 2010.

Os explantes utilizados para o ensaio fo- ram segmentos nodais de videira cultivar Bordô (Vitis labrusca), contendo uma gema axilar de aproximadamente $1 \mathrm{~cm}$ e uma folha, excisados de plantas preestabelecidas in vitro. Os explantes foram introduzidos em frascos de vidro com capacidade de $100 \mathrm{~cm}^{3}$ e fechados com tampa plástica de rosca contendo $20 \mathrm{~cm}^{3}$ de meio de cultura. $\mathrm{O}$ meio de cultura utilizado foi o MS (Murashige \& Skoog, 1962) acrescido de 6 g. $\mathrm{dm}^{3}$ de Ágar (Sigma) e 30 g.dm ${ }^{3}$ de sacarose.

Para os óleos essenciais de melaleuca (Melaleuca alternifolia) e calêndula (Calendula officinalis) foram feitos dois ensaios com diferentes concentrações, sendo o primeiro ensaio com 0; 10; 20; 40; $80 ; 100 \mathrm{~mm}^{3} \cdot \mathrm{dm}^{-3}$ e o segundo com 0, 50, 100; $150 ; 200 ; 250 \mathrm{~mm}^{3} \cdot \mathrm{dm}^{-3}$.

Para Dalbergia monetária foram testados o extrato aquoso submetido à secagem por spray dry e o extrato submetido à secagem por liofilização, ambos testados nas concentrações $0,50,100$, 150,200 e $250 \mathrm{~mm}^{3} \cdot \mathrm{dm}^{-3}$. Todos os compostos foram adicionados ao meio de cultura MS antes da inserção das plântulas.

$\mathrm{O} \mathrm{pH}$ do meio de cultura MS foi ajustado para 5,8 com $\mathrm{NaOH} 0,1 \mathrm{~N}$ antes da adição de ágar. Em seguida os meios foram esterilizados em autoclave a $120^{\circ} \mathrm{C}$ durante $20 \mathrm{~min}$.

Os experimentos foram mantidos em sala de crescimento climatizada, com fotoperíodo de 16 horas de luz, fornecidas por lâmpadas fluorescentes do tipo luz do dia, intensidade luminosa de aproximadamente $20 \mu \mathrm{mol} \mathrm{m} \mathrm{m}^{-2} \mathrm{~s}^{-1}$ e temperatura de $25 \pm$ $1^{\circ} \mathrm{C}$. O experimento foi realizado em delineamento inteiramente casualizado com quatro repetições por tratamento. A unidade experimental foi constituída de 1 frascos contendo 4 explantes.

As avaliações foram realizadas 60 dias a partir da instalação do experimento e os parâmetros observados foram: número de estacas por explante, número de folhas, comprimento médio dos brotos (cm), número de raízes por estaca, comprimento da raiz principal $(\mathrm{cm})$ e biomassa fresca da parte aérea (g).

\section{RESULTADOS E DISCUSSÃO}

Para o extrato aquoso de DM secado por spray dry, houve variação com comportamento quadrático das concentrações utilizadas, para os parâmetros comprimento da raiz principal, número de folhas, comprimento médio dos brotos e número de estacas.

No comprimento da raiz principal (Figura 1) e no comprimento médio dos brotos (Figura 2), observa-se que inicialmente o extrato não foi efetivo, porém, a partir de $140 \mu \mathrm{l}$ ele passa a ser efetivo tanto no comprimento das raízes quanto no comprimento médio dos brotos já que o aumento do número de raízes permite maior absorção de nutrientes e acarreta maior crescimento da plântula. Entretanto Good et al. (2007), analisando o mesmo extrato na micropropagação do porta-enxerto VR-043-43, observou que este foi mais efetivo no crescimento da parte aérea, não influenciando o desenvolvimento do sistema radicular, porém utilizaram o meio MS 
SPINARDI, B. et al. Extratos vegetais...

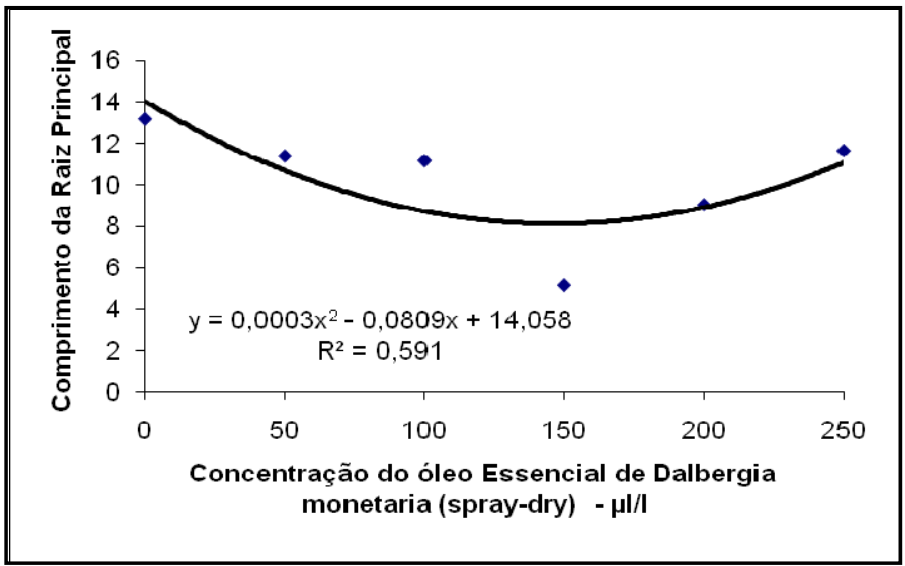

FIGURA 1 - Efeito da adição do extrato aquoso de Dalbergia monetaria (spray dry) em meio de cultura MS, sobre o comprimento da raiz principal em videira cv. Bordô, 60 dias após a implantação do experimento. Ponta Grossa - PR. 2009.

ter influenciado a diferença de resultados.

Houve efeito linear negativo para o número de folhas (Figura 3) e número de estacas (Figura 4) para DM spray-dry. O aumento da concentração do extrato ocasionou redução do número de folhas, o que pode ter influenciado na redução do número de estacas e vice versa, sendo um efeito sinérgico para ambos os parâmetros pois, a redução do número de folhas diminui a taxa fotossintética e por conseqüência, gera o que pode ser considerado um atraso no crescimento vegetal, reduzindo o tama- por broto. No trabalho realizado por Good et a.l (2007), não foi feito análise do número de folhas, o que dificulta uma comparação entre cultivares e concentrações do extrato.

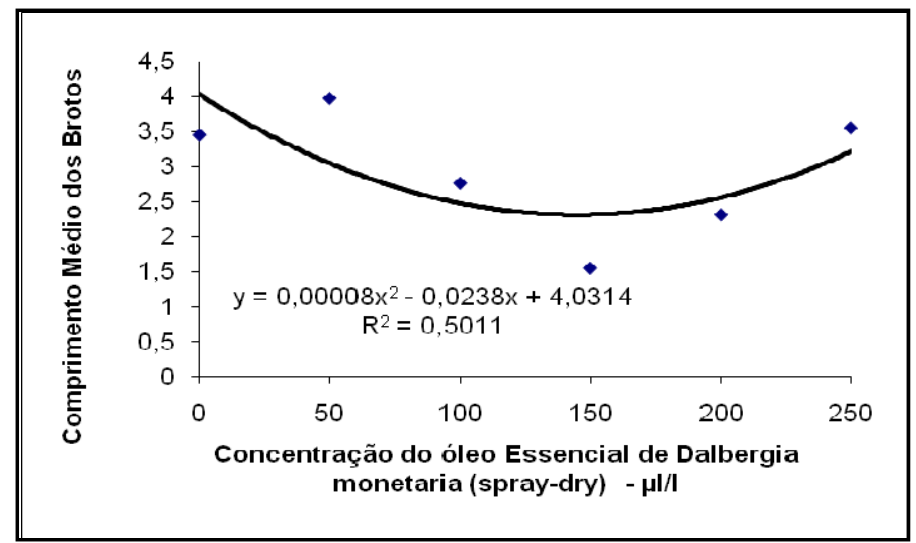

FIGURA 2- Efeito da adição do extrato aquoso de Dalbergia monetaria (spray dry) em meio de cultura MS, sobre o comprimento médio dos brotos em videira cv. Bordô, 60 dias após a implantação do experimento. Ponta Grossa - PR. 2009. 
SPINARDI, B. et al. Extratos vegetais...

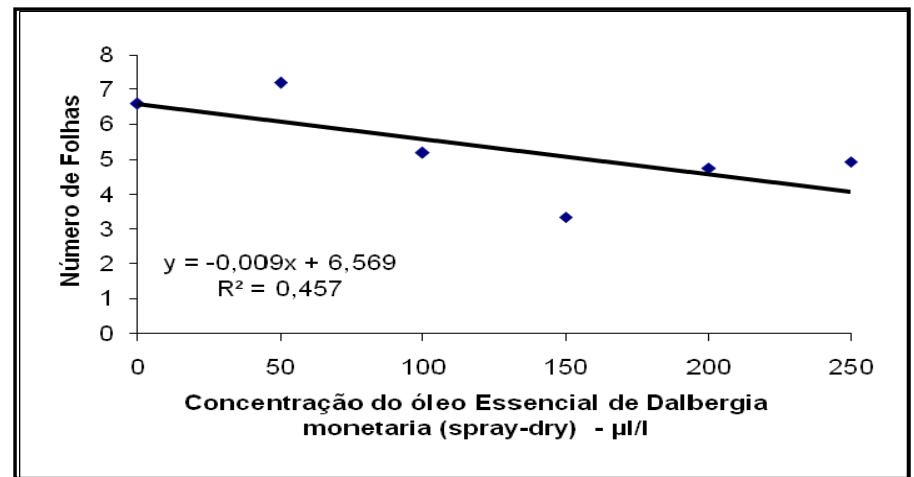

FIGURA 3- Efeito da adição do extrato aquoso de Dalbergia monetaria (spray dreier) em meio de cultura MS, sobre o número de folhas em videira cv. Bordô, 60 dias após a implantação do experimento. Ponta Grossa PR. 2009.

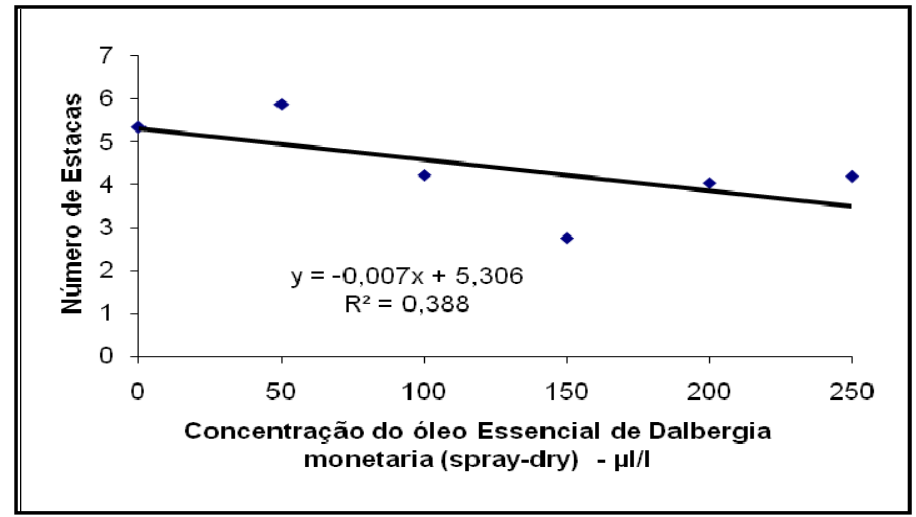

FIGURA 4- Efeito da adição do extrato aquoso de Dalbergia monetaria (spray dreier) em meio de cultura MS, sobre o número de estacas em videira cv. Bordô, 60 dias após a implantação do experimento. Ponta Grossa PR. 2009.

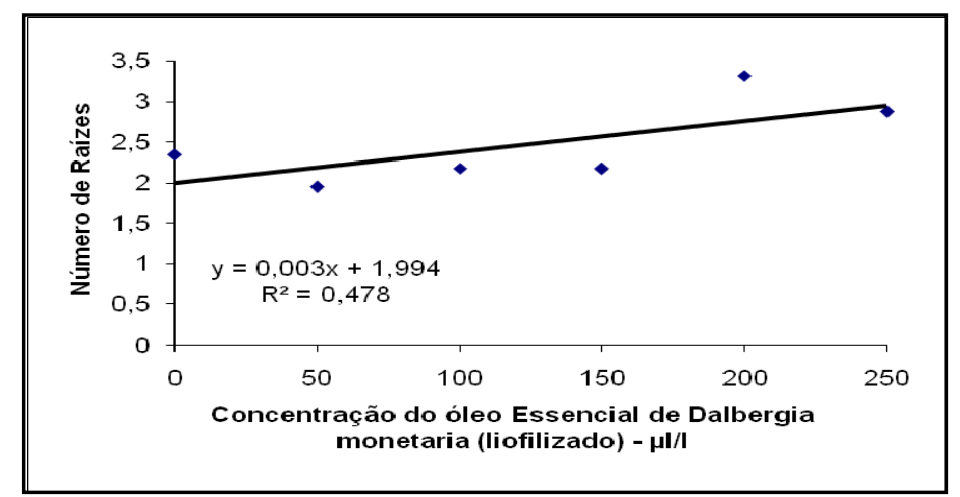

FIGURA 5- Efeito da adição do extrato aquoso de Dalbergia monetaria (liofilizado) em meio de cultura MS, sobre o número de raízes em videira cv. Bordô, 60 dias após a implantação do experimento. Ponta Grossa PR. 2009. 
SPINARDI, B. et al. Extratos vegetais...

Para DM liofilizado, houve efeito linear significativo apenas para o número de raízes (Figura 5), onde as maiores concentrações acarretaram maior número de raízes, diferindo do resultado obtido por Good et al (2007) onde não houve influência do extrato de DM no crescimento radicu- lar para o porta-enxerto VR-043-43, o que pode estar relacionado à diferença das cultivares, da concentração do extrato utilizado e também relacionado à diferença na concentrações de sais do meio de cultura, uma vez que Good et al. (2007) utilizaram o meio MS com a metade da concentração de sais.

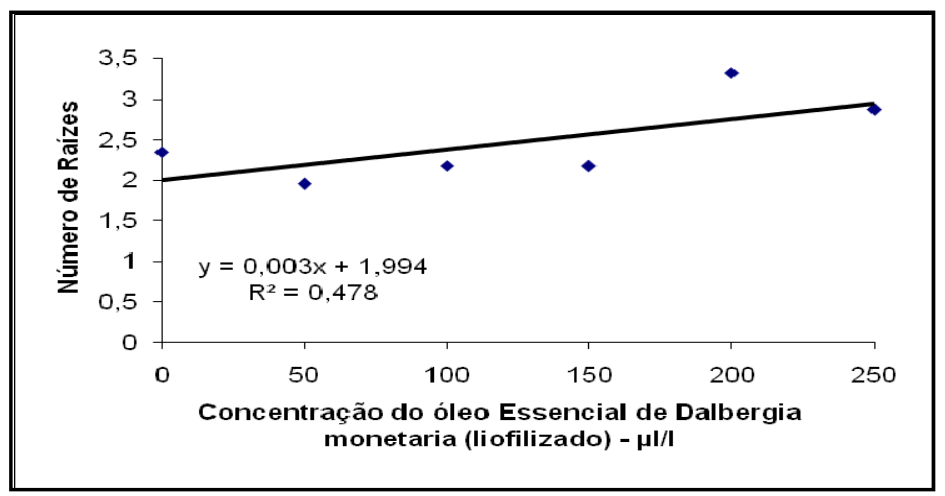

FIGURA 5- Efeito da adição do extrato aquoso de Dalbergia monetaria (liofilizado) em meio de cultura MS, sobre o número de raízes em videira cv. Bordô, 60 dias após a implantação do experimento. Ponta Grossa PR. 2009.

Não houve influencia do óleo essencial de Calendula officinalis no desenvolvimento vegetativo da cv. Bordo, sendo possível testar os efeitos antivirais posteriormente, porém, sem alteração significativa de crescimento e desenvolvimento vegetal.

Houve efeito linear negativo do óleo essencial de Melaleuca alternifolia com o aumento da concentração para o número de estacas (Figura 6).

Dessa maneira, pode-se fazer o uso tanto dos óleos quanto dos extratos, sem prejuízos no crescimento e desenvolvimento vegetal, uma vez que nenhuma das substâncias apresentou-se fitotóxica à cv. Bordô.

\section{CONCLUSÃO}

O uso dos extratos aquosos de Dalbergia monetaria (spray-dry e liofilizado) e dos óleos essenciais de Melaleuca alternifolia e Calendula officinalis, não foram significativos na micropropagação de videira cv. Bordô, porém não foram fitotóxicos, permitindo assim a continuação dos estudos de seu possível poder antiviral.

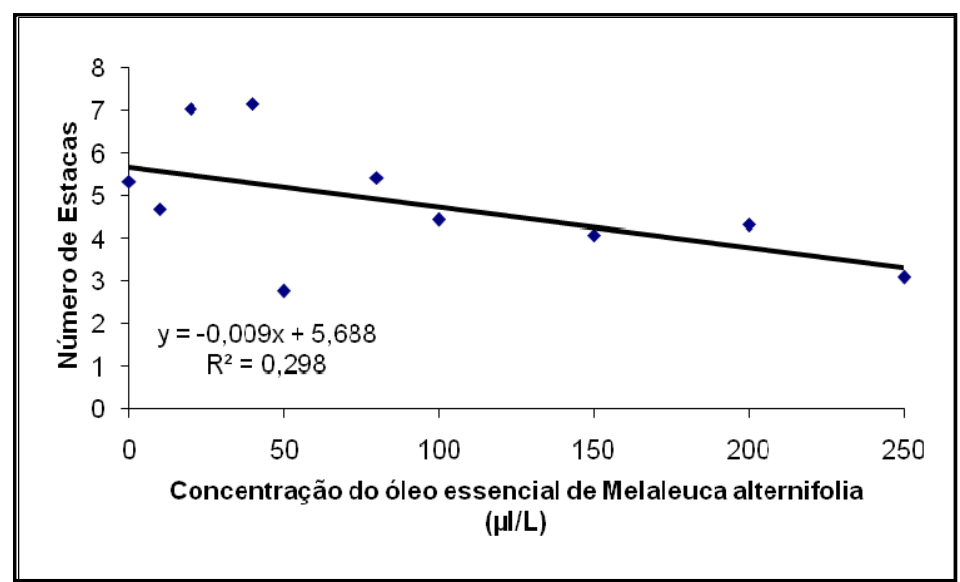

FIGURA 6- Efeito da adição do óleo essencial de Melaleuca alternifolia em meio de cultura MS, sobre o número de estacas em videira cv. Bordô, 60 dias após a implantação do experimento. Ponta Grossa - PR. 2009. 
SPINARDI, B. et al. Extratos vegetais...

\section{REFERÊNCIAS}

1. BISHOP, C. D. Antiviral activity of the essential oil of Melaleuca alternifolia (Maiden \& Betche) Cheel (tea tree) against tobacco mosaic virus. J. Essent. Oil Res. 7:641-644. 1995.

2. BOTELHO, R.V.; PIRES, E. J. P. Viticultura como opção de desenvolvimento para os Campos Gerais. II Encontro de Fruticultura dos Campos Gerais. UEPG. Anais, p.(40-54). 2009.

3. CAMARGO, U.A. Uvas do Brasil. Brasília: Empresa Brasileira de Pesquisa Agropecuária, Uva e Vinho - SPI. Documentos 09. 90p. 1994

4. COLETTO, L.S.; MARTINS, C.R.; GOULART, M. Micropropagation of stock for grafting of grapevine Paulsen 1103 "in vitro", with different citocinina concentrations. Revista da FZVA, Uruguaiana, v.15, n.1, p. 102-108, 2008.

5. DZAZIO, P.M.; BIASI, L.A.; ZANETTE, F. Micropropagação do porta-enxerto de videira 420-A. Revista Brasileira de Fruticultura, Jaboticabal, v.24, n.3, p. 759-764, 2002.

6. GOOD Maiara ; NUNES, S. N ; AYUB, R. A. . Efeitos do extrato aquoso de Dalbergia Monetaria L. na micropropagação do porta-enxerto de videira VR043-43. In: VII Encontro de pesquisa EPUEPG, 2007, Ponta Grossa. Anais do VII Encontro de pesquisa EPUEPG. Ponta Grossa : UEPG, 2007. v. 1. p. 1-1.

7. KALVATCHEV Z; WALDER R; GARZARO D. 1997. Anti-HIV activity of extracts from Calendula officinalis flowers. Biomedical Pharmacotheraphy, 51: 176-180.

8. NUNES, D. S.; HAAG, A.; BESTTMAN, H. J. Two new proanthocyanidins from the bark of Dalbergia monetaria. Phytochemistry, v. 28, n. 8, p. 2183-2186, 1989.

9. RIZZON, L. A.; MIELE, A.; MENEGUZZO, J. Avaliação da uva cv. Bordô para a elaboração de vinho tinto. Ciência e Tecnologia de Alimentos, v. 20, n. 1, p. 115-121, 2000.

10. ROBERTO, S.R.; PEREIRA, F.M.; BOLIANI, A.C.; DA SILVA, A.C.C. Origem, botânica e biologia da videira. In: Corrêa LS, Boliani AC, Fracaro AA (Eds.). Uvas rústicas: Cultivo e processamento em regiões tropicais. Jales, [s.n], Editora Gráfica Universitária, p. 30-50, 2008.

11. TEIXEIRA, A.H.C.; DE SOUZA, R.A.; RIBEIRO, P.H.B. Aptidão agroclimática da cultura da videira no Estado da Bahia, Brasil. Revista Brasileira de Engenharia Agrícola e Ambiente, v. 6, n. 1, p. 107-111, 2002.

12. ZANUZ, M.C. Efeito da maturação sobre a composição do mosto e qualidade do suco de uva. Porto Alegre, 1991. 117p. Dissertação (Mestrado em Agronomia) - Faculdade de Agronomia, Universidade Federal do Rio Grande do Sul, RS

Recebido em 24/05/2010

Aceito em 05/12/2011 